\title{
Ambivalence for Cognitivists: A Lesson from Chrysippus?
}

\author{
Bill Wringe \\ Bilkent University
}

\begin{abstract}
Ambivalence-where we experience two conflicting emotional responses to the same object, person or state of affairs - is sometimes thought to pose a problem for cognitive theories of emotion. Drawing on the ideas of the Stoic Chrysippus, I argue that a cognitivist can account for ambivalence without retreating from the view that emotions involve fully-fledged evaluative judgments. It is central to the account I offer that emotions involve two kinds of judgment: one about the object of emotion, and one about the subject's response.
\end{abstract}

Keywords emotion; cognitivism; ambivalence; neo-stoicism; phenomenology

DOI:10.1002/tht3.243

\section{Examples and a thesis}

Consider three instances of ambivalence.

Rival: Patricia hopes to become Chair of her department. She enjoys a friendly professional rivalry with a colleague, Ian. On hearing that Ian has been preferred for the post of Chair, she experiences simultaneous disappointment and happiness. (Greenspan 1980)

Cid: Ximene is deeply in love with Rodrigo until he accidentally kills her father. Subsequently Ximene comes to hate and resent Rodrigo, while remaining in love with him. (Carr 2009)

Beckert: On watching Fritz Lang's film $M$ James is simultaneously moved by disgust for its protagonist, the child-murderer Beckert, and sympathy for his plight as he becomes the target of a gang of criminals who try him in a kangaroo court. (Harold 2010)

In each scenario an individual experiences conflicting emotions. However, we may well think that Patricia, Ximene and James need not be rationally deficient in any way. A plausible account of emotion needs to explain how such situations are possible. ${ }^{1}$ It should also account for our intuition that none of these individuals need be guilty of irrationality, by either vindicating it, or explaining it away.

Ambivalence is often thought to present a problem for cognitivist accounts of emotion. ${ }^{2}$ How deep the problem runs is controversial. Clarity is not enhanced by disagreements as to exactly which accounts count as cognitivist. I shall apply the label

Correspondence to: E-mail: billwringesemail@gmail.com 
broadly. Paradigmatic instances of cognitivism will be views on which emotions are constituted either wholly or partly by judgments; but I shall take views on which emotions are wholly or partly constituted by states which are less committal than all-out judgments, such as thoughts, or by intentional states which have a distinct functional role from judgments, such as perceptual states, to count as cognitivist. I shall take accounts on which specifying the propositional content of an emotion plays a significant role in specifying which emotion we are talking about to count as members of the broad family, unless there are significant considerations against doing so.

Contemporary cognitivist accounts of emotions cannot account adequately for the phenomenon of ambivalence. Such accounts need either to explain why ambivalence can be a rational response to a situation, or to explain why it can often seem so. They should also account for certain aspects of the phenomenology of ambivalence. Cognitivists who attempt to account for ambivalence have typically concentrated on the first of these tasks and neglected the second.

However, cognitivists should not lose heart. One version of cognitivism enables us to retain the core cognitivist commitment to the idea that emotions have propositional content, and allows us to do justice both to the potential rationality of ambivalent responses, and to their phenomenology. It is based on views of the Stoic Chrysippus, as presented to us in Cicero's Tusculan Disputations, and canonically reconstructed by Sorabji (2000). A distinctive feature of Chrysippus's view, as Sorabji presents it, is that he takes emotions to involve two different kinds of judgment: one about evaluative features of our situation, and the other about our bodily response to that situation. By appealing to these two different kinds of judgment, we can account both for the apparent rationality of at least some instances of ambivalence, and for their distinctive phenomenology.

This paper is not intended primarily as a work of historical exegesis. I shall make few - perhaps no - original exegetical suggestions. Furthermore, the aspects of Chrysippus's view which I recommend are independent of, and require no commitment to, other aspects of his position which have little to recommend them, such as his view that the majority of everyday human emotional responses are irrational. ${ }^{3}$ Indeed, in claiming that some instances of ambivalence are, or can seem rational, I commit myself to a position which Chrysippus and other Stoics would have rejected. I am arguing that Chrysippus's account was better than he could have recognized: it accounts for phenomena which his broader philosophical commitments would have prevented him from acknowledging.

\section{Cognitivism and rational ambivalence}

Within the cognitivist framework, ambivalence is most naturally understood as involving a commitment to judgments with incompatible contents. Thus, we might see Patricia, who is simultaneously happy and disappointed, as judging both that that is terrible that Ian has been promoted, and that it is good that he has been; Ximene as believing both that Rodrigo is malign and destructive, and that he is a fundamental source of good in her life; and James as believing that Beckert both deserves and does not deserve his fate. Since 
an individual cannot be committed to incompatible judgments without being irrational accounts of this sort cannot allow for cases where ambivalence appears rational.

Should we allow for them? Greenspan (1980) has argued, prominently, that we should. As she points out, 'irrational' is typically a term of reproach. And yet, Greenspan emphasizes, there might be nothing wrong with the combination of attitudes manifested in Rivals. But if there is nothing wrong with this combination of attitudes, then they seem to be exempt from criticism, and a fortiori exempt from criticism on grounds of irrationality.

This argument relies on the idea that there is nothing wrong with the emotions involved in Rivals. One might go further, and suggest that in each of the cases discussed in Section 1 an ambivalent response is superior to one that avoids ambivalence. For we might think that a response that avoids ambivalence fails to give due acknowledgment to the values at stake in the two conflicting responses. If Patricia were not ambivalent, she would fail to give due acknowledgment either to her own claims or those of her rival; if Ximene were not ambivalent, she would fail to acknowledge both the value that Rodrigo has in her life and the loss she has experienced through the death of her father; if James were not both disgusted and sympathetic he would be failing to acknowledge either the awfulness of Beckert's crimes, or the fact that despite those crimes he is being treated wrongly.

Someone might hold that Patricia, Ximene and James are rightly exempted from criticism, but nevertheless irrational. They might suggest that in assessing the rationality of a set of attitudes and in addressing whether they were the best set of attitudes to have overall one was involved in two separate kinds of evaluation by reference to two different kinds of standard. Or they might suggest that the responses exemplified in a case like Rivals were only ideal when considered as examples of the kinds of responses which real-life human beings could be expected to have.

These points seem like good counters to the first line of argument; but they do not address the second. If ambivalent responses are better than non-ambivalent responses in the scenarios we have considered, then in judging them to be immune from criticism, we are not simply saying that they are the best responses we can manage given understandable human limitations, but the most adequate response to the situations involved. ${ }^{4}$

Cognitivists have responded to this problem in two different ways. A cognitivist might retreat from the claim that emotions involve judgments to the idea that they involve some kind of cognitive state of a kind $\mathrm{K}$ which has the following property: a subject can be in a K-state with respect to two incompatible propositions without thereby being guilty of irrationality. Eligible K-states include thoughts (Stocker 1987); taking pleasure or pain in a given thought (Greenspan 1988); half-hearted beliefs (Harold 2010); or perceptual states (de Sousa 1987).

Alternatively, or additionally, the cognitivist may construe the contents of the propositional state involved in ambivalent emotions in such a way as to ensure that they do not conflict. This may involve claiming that the emotion-constituting states are directed at different objects, different aspects of the same object, or compatible, yet contrasting, properties of the same object (Tappolet 2005). Thus Patricia might judge that it is bad 
that the department will not flourish under her stewardship, while judging it good that Ian has been rewarded for his hard work; Ximene may believe that Rodrigo is a source of good in her life but also a danger to those around her; and James that Beckert deserves some form of punishment, but not the vigilante justice he actually receives.

Accounts of either sort can explain why ambivalence need not involve irrationality. However, as I shall now argue, they cannot provide us with a convincing account of the phenomenology of ambivalence.

\section{The phenomenology of ambivalence}

Ambivalence typically seems to involve some kind of experience of conflict. Our awareness of the tension involved in ambivalence is felt as part of the emotions involved, rather than something of which we have a detached and independent awareness. Consider two ways of developing the case of Cid. In one case, Ximene alternates between episodes in which she experiences a burning hatred for Rodrigo and ones in which she is overwhelmed by love for him. In the second case both the love and the hatred she experiences are present in her mind at the same time, along with the discomfort that the compresence of these emotions involves. ${ }^{5}$ Although both versions of the scenario will involve the same kind of conflicting K-states, only the second involves the kind of ambivalence which is a challenge to the cognitivist.

The second way of developing Cid seems to involve a felt element, over and above the alternating experiences of hate and love in the first case, which the first scenario does not. Characterizing this felt element accurately is tricky. It need not involve a sense of discomfort. Consider Beckert. Harold (2010) points out that in appreciating $M$ we may take pleasure in film-maker's ability to present us with a scenario that shows us just how 'messy' the world is, when compared to the simplistic categories that our initial moral judgments incline us towards. ${ }^{6}$ Discomfort need not be involved. Perhaps emotional responses to fiction are a marginal case. ${ }^{7}$ If so, we should not rely on them in trying to characterize the phenomenology of ambivalence.

However, Greenspan (1980) suggests that cases like Rival also show that ambivalence need not involve discomfort. She also notes that we do not always seek to resolve the conflict or tension which is characteristic of ambivalence, emphasizing that in a situation like Rival, emotional maturity may involve a recognition of the incompatibility of two good states of affairs, and suggesting that one might regard this as something which constitutes part of the richness of life rather than something to be lamented. However, while a mature esthetic or moral sensibility may involve an appreciation of emotional states characteristic of scenarios like Rival and Beckert, it is hard to characterize the kind of excellence of sensibility involved in this appreciation, without describing it as involving a distinctive response to a kind of conflict. Indeed it is natural to see ambivalence as involving not simply a conflict between attitudes, but some kind of experience of conflict. One's experience is that of being in a state which calls for some kind of resolution.

One metaphor which suggests itself in this context is that of an unresolved discord in a piece of music, which calls for a resolution which it may or may not receive. Notice that 
tensions of this sort need not be unpleasurable. Part of the skill of the composer lies in using them to beautiful effect. Nevertheless they can only do so by exploiting the fact that the chord itself seems to demand some kind of resolution.

A good account of the emotions should enable us to explain the phenomenology of ambivalence. A cognitivist might point to the fact that the emotions involved have contrary contents. However, in explaining why ambivalence need not be irrational, the accounts we have considered seem to have deprived us of the resources needed to explain the sense in which ambivalence involves conflict. If ambivalent emotions involve having thoughts, beliefs or judgments which are not incompatible with one another, it is unclear why ambivalence should present itself to us as something which needs to be resolved. ${ }^{8}$ And if ambivalent emotions involve K-states of a sort that do not preclude a rational individual from holding $\mathrm{K}$ to both of the propositions $\mathrm{p}$ and not $\mathrm{p}$, it is unclear why there should be any tension involved here.

\section{Historical disclaimers}

I shall now argue that Chrysippus's account of emotions provides us with the materials for constructing a more satisfactory account of the phenomenon of ambivalence than contemporary cognitivist views do. The view I shall put forward will involve a commitment to Stoic views about the kinds of states emotions are, and to a distinctively Stoic view about the kinds of judgment that emotions involve. ${ }^{9}$ However, it will not involve any commitment to another distinctively Stoic view about the emotions - namely that they typically involve false beliefs - and in particular, false beliefs about the good. ${ }^{10}$

Ambivalence would probably not have seen particularly salient, or particularly interesting phenomenon to historical exponents of Stoicism. The Stoics were interested in one kind of phenomenon which we might characterize as a form of emotional conflict, namely conflicts between reason and emotion. Accounting for the possibility of conflicts of this sort seems to have been central to Chrysippus's discussion of Euripides' Medea. ${ }^{11}$ The kinds of conflict I have been dealing with here are rather different: conflicts between two different emotions.

The Stoic commitment to the idea that emotions typically involve false beliefs may explain why Stoics do not discuss conflicts between different emotions. On a Stoic view, such conflicts would have involved conflicts between several false beliefs. Conflicts between such beliefs, and any discomfort to which they might give raise, are unlikely to have seemed surprising to Stoics. The idea that false beliefs can conflict with one another is scarcely puzzling. Similarly, no Stoic would have been committed to the project of explaining the rational acceptability, or apparent rational acceptability of ambivalent emotions. Finally, the kind of discomfort or tension involved in ambivalence is unlikely to have seemed especially interesting to someone who thinks, as the Stoics did, that any false beliefs about matters of value are likely to lead to mental disturbance.

It is therefore surprising and significant that Chrysippus's view provides us with the resources to construct an account of ambivalence which is superior to the modern 
cognitivist accounts which I have discussed in Section 2. For, as I shall now argue, it does precisely this.

\section{How Chrysippean cognitivism solves the problems}

For Chrysippus, emotions involve two kinds of judgment. One concerns the external world: typically it will have as its content that something good or bad is present. (Call this an E-judgment.) The second judgment has as its object a response to the object of the first judgment. (Call this an R-judgment.) Typically Chrysippus talks of 'expansion' and 'contraction' in the R-judgments.

Chrysippus's account does not make much room for individual objects, or particular aspects of objects to be the intentional objects of emotions. However, it can easily be amended to allow for this. It can also be adapted to cover a wider range of emotions than the four typically recognized by the Stoics. We could either allow a wider range of evaluative propositions to figure in emotions than the Stoics do, or characterize the physiological responses involved in the R-judgments more finely than they do. We also need not accept the Stoic view that the E-judgments involved in the majority of human emotions are false. The amended view is still distinctive: it differs from contemporary forms of cognitivism insofar as it is committed to the idea that emotions involve a pair of judgments and insofar as the content of one of those judgments refers to the appropriateness of a response.

What are expansion and contraction? Presumably, they involve some kind of physical response to the object or situation exciting the emotion. But this under-determines matters. We might take expansion and contraction to be involuntary physiological reflexes. ${ }^{12}$ Since Chrysippus does not hold that expansions and contractions themselves are constitutive of emotions, but only that R-judgments about them are, his view is compatible with the existence of (token) emotions that are not expressed bodily. ${ }^{13}$ Nevertheless on this interpretation the view may require that there are physiological responses which are characteristic of particular emotion-types. It also requires us to be able to make judgments about these physiological responses. This seems implausible: even if there are involuntary physiological changes characteristic of different emotions, we often lack the concepts necessary to make judgments about them.

Alternatively we might take see expansions and contractions to be voluntary actions motivated by the presence or absence of some good. Since backward-looking emotions such as sadness need not motivate any kind of voluntary action this leaves us with an implausible account of emotion. ${ }^{14}$ However a third possibility seems more promising. This is to take 'expansion' and 'contraction' to be generic names for ways in which emotions can be expressed in action as we do when we weep out of grief or cheer out of joy. These forms of expression stand at a range of different points on a continuum between fully voluntary actions aimed at satisfying some goal of the agent and involuntary physiological reflexes (Hursthouse 1991). There seem to be characteristic forms of expression associated with many emotions. Furthermore, unlike involuntary reflexes 
these forms of expression in action seem to be the kinds of thing that we can recognize and can and do judge to be appropriate (or inappropriate) to a situation.

On the amended Stoic view, we might see Patricia's disappointment in Rivals as involving the following judgments:

DE: The evil of my not being head of department is present.

DR: Contraction is appropriate.

One the same view her happiness involves the following judgments:

PE: The good of my colleague's being head of department is present.

PR: Expansion is appropriate.

If we focus only on the judgments PE and DE, we will not see Patricia as irrational, since $\mathrm{PE}$ and $\mathrm{DE}$ can both be true. However matters seem more complicated once we consider the judgments PR and DR.

If PR and DR are 'all-out' judgments, they seem incompatible with one another. If so ambivalence will involve a kind of irrationality. ${ }^{15}$ Still this view explains why we do not typically take ambivalence to involve irrationality. When assessing whether an ambivalent individual is irrational, we overlook the possibility of beliefs such as PR and DR. Once our attention is drawn to them, we can see that ambivalence does involve a kind of irrationality.

Still, there is more to say. The terms 'expansion' and 'contraction' seem like labels for states which exclude one another on logical grounds. However, I suggested that we should interpret Chrysippus' account as making reference to paradigmatic expressive responses such as cheering and weeping. Logic does not rule out the possibility of someone simultaneously weeping and cheering. However, perhaps something else does: namely human physiology. If contraction and expansion are understood as involving fully voluntary actions, this might seem implausible: it's natural to think we have a range of responses at our disposal, which need not all be incompatible with one another. But if we see these forms of expression as standing somewhere between voluntary actions and reflexes, physiology can play a role in explaining the incompatibility. ${ }^{16}$

This view accounts for almost all of the phenomena. But we might instead take PR and DR to be provisional judgments. Represent their contents as follows:

PRP: Insofar as some good is present, expansion is appropriate.

DRP: Insofar as some evil is present, contraction is appropriate.

Now Patricia is committed to holding that

PE: The good of my colleague's being head of department is present.

DE: The evil of my not being head of department is present.

PRP: Insofar as some good is present, expansion is appropriate.

DRP: Insofar as some evil is present, contraction is appropriate.

Since these beliefs are consistent with one another, Patricia's emotional state need involve no irrationality. This is as it should be. Furthermore, this view provides a natural explanation of the phenomenology of ambivalence. Although PRP and DRP are mutually 
consistent, there is a tension between them. We might see judgments like these as seeking resolution in the form of an all-out judgment of the appropriateness of either contraction or expansion, and of the occurrence of the relevant expressive responses. When both responses cannot occur, together, we have an unresolved conflict. Hence the tension we take to be characteristic of ambivalence: a tension we can expect to be reflected in our experience to the extent that the judgments which give rise to it may also be; and which depending on our character, we may either find uncomfortable or enjoy. So this account may be better than the last.

How essential to this account are the distinctively Chrysippean judgments about the appropriateness of contraction and expansion? Might it be enough to see emotions as consisting of prima facie judgments with contents such as DE and PE, and the tension which is part of ambivalence to be something which arises out of a need to resolve these two judgments into some kind of overall judgment of the goodness or badness of my situation as a whole ${ }^{17}$ I think not: there is no reason to see all-out judgments of the form DE and PE as conflicting. It is equally unclear why failure to resolve prima facie judgments with these contents should generate any kind of discomfort. There seems nothing obviously troubling about an all-out judgment to the effect that my situation is in some respects good and in some respects bad. So the distinctively Chrysippean judgments are indeed essential here. ${ }^{18}$

\section{Notes}

1 Pugmire $(1996,2005)$ argues that cases of what he calls 'whole-hearted' ambivalence are not possible. Perhaps he would regard not Rival and Cid as involving ambivalence of this sort. But they seem to be genuine possibilities which an adequate account of emotions needs to account for. (For Pugmire's view of cases like Beckert, see footnote 8.)

2 Greenspan (1980) appeals to ambivalence to argue against the view that emotions are a kind of judgment. Morton (2002) and Tappolet (2005) suggest the problem affects other kinds of cognitivist.

3 In attempting to separate Stoic accounts of emotions from specifically Stoic claims about value I follow the precedent of Nussbaum (2002). But I take her account of Stoic theories of emotion to be inferior to Sorabji's.

4 Luke Brunning raised this issue.

5 We can also imagine cases without discomfort. They are not interesting in this context.

6 Indeed Walton (1978) denies that the emotion-like states that works of fiction arouse in us are genuine states of emotion. If so, then Beckert does not provide us with a genuine case of emotional ambivalence.

7 Pugmire (1996) suggests this is true because of the kind of detachment characteristic of aesthetic appreciation, although he also suggests other kinds of ambivalence may involve related forms of detachment.

8 This counts against Tappolet's (2005) proposal in particular.

9 My account of Chrysippus's view, and of its distinctive 'two judgments' feature relies heavily on Sorabji (2000). 
10 The restriction to what is typical here will matter to historians. On the standard Stoic view, only the emotions of the ordinary person involve false beliefs about the good. Things will be different where the Stoic sage is concerned. But the restriction makes little difference here: Stoic sages are rare, and the characters whose predicaments we have been considering are unlikely candidates for sage-hood.

11 See Gill (1983) and, for a useful overview of subsequent discussion Graver (2007, pp. $71 \mathrm{ff}$ ). Our evidence for Chrysippus's interest in this issue comes from Galen's reports of his views in the Principles of Hippocrates and Plato. See also Tieleman $(1996,2003)$ for attempts at a comprehensive reconstruction of Chrysippus's account.

12 This seems to be Sorabji's view.

13 Could there be emotion types that have no characteristic bodily expression? Perhaps. On my account, emotions of this sort will not give rise to the phenomenology characteristic of ambivalence.

14 As one referee noted.

15 It will, however, be a kind of irrationality which, on the Stoic view, it is feasible to avoid: as Sorabji documents in detail, much Stoic writing on the emotions takes as its theme the way in which we can avoid unwanted emotions by getting rid of R-judgments.

16 Ambivalent states involving different pairs of emotions would presumably involve different pairs of incompatible physical responses. One might wonder - as one referee did - whether everything we typically count as a positive emotion involves a response incompatible with some response to a negative emotion? I find it plausible that something of this sort underlies our folk classifications of emotions as positive and negative.

17 As one referee suggested.

18 I thank two anonymous referees for very helpful comments. Earlier versions were presented to audiences in Ankara Warwick and Pisa: on each occasion, I found the discussion extremely valuable.

\section{References}

Carr, D. "Virtue, Mixed Emotions and Moral Ambivalence." Philosophy 84 (2009): 31-46.

Gill, C. “Did Chrysippus Understand Medea?” Phronesis 28 (1983): 136-49.

Graver, M. Stoicism and Emotion. Chicago: University of Chicago Press, 2007.

Greenspan, P. "A Case of Mixed Feelings: Ambivalence and the Logic of Emotion," in Explaining Emotions, edited by A. O. Rorty. Berkeley: University of California Press, 1980.

Emotions and Reasons: An Inquiry into Emotional Justification. New York: Routledge, 1988.

Harold, J. "Mixed Feelings: Conflicts in Emotional Responses to Film." Midwest Studies in Philosophy 34 (2010): 280-94.

Hursthouse, R. "Arational Actions." Journal of Philosophy 88 (1991): 57-68.

Morton, A. "Emotional Accuracy." Proceedings of the Aristotelian Society 76 (2002): 265-75.

Nussbaum, M. The Therapy of Desire: Theory and Practice in Hellenistic Ethics. Princeton, NJ: Princeton University Press, 1994.

—. Upheavals of Thought. Cambridge: Cambridge University Press, 2002.

Pugmire, D. "Conflicting Emotions and the Indivisible Heart." Philosophy 71 (1996): 27-40.

- Sound Sentiments: Integrity in the Emotions. Oxford: OUP, 2005.

Sorabji, R. Emotion and Peace of Mind. Oxford: OUP, 2000.

de Sousa, R. The Rationality of Emotion. Cambridge: MIT Press, 1987.

Stocker, M. “Emotional Thoughts.” American Philosophical Quarterly 24 (1987): 59-69. 
Tappolet, C. “Ambivalent Emotions and the Perceptual Account of Emotions.” Analysis 65 (2005): 229-33.

Tieleman, T. L. Galen and Chrysippus on the Soul. Argument and Refutation in the De Placitis Books II-III. Leiden: Brill, 1996. 2003.

Walton, K. "Fearing Fictions." Journal of Philosophy 75 (1978): 5-27. 